\title{
KEBIJAKAN DAN APLIKASI KESELAMATAN PASIEN
}

\author{
Putri Leony Hasibuan / NIM : 181101058 \\ Putrileony1@gmail.com
}

\begin{abstract}
Abstrak
Instansi pelayanan Rumah Sakit serta tenaga medis menjadi peranan penting dalam menerapkan kebijakan yang dapat mendukung keselamatan pasien. Dengan banyaknya jumlah pengguna pelayanan kesehatan tentu ingin mendapatkan pelayanan yang berkualitas. Rumah Sakit dan tenaga medis wajib bekerja sama dalam membuat kebijakan yang dapat mendukung keselamatan pasien selama pasien berada di Rumah Sakit. Penelitian ini dilakukan untuk mengetahui kebijakan yang akan dilakukan dalam mendukung keselamatan pasien. Penelitian ini dilakukan dengan menggunakan metode deskriptif dimana penelitian ini dilakukan berdasarkan pengumpulan data yang ada pada buku textbook maupun jurnal.

Kata Kunci : Kebijakan, Perawat, Keselamatan Pasien
\end{abstract}

\section{Latar Belakang}

Banyaknya pengguna pelayanan kesehatan menjadi acuan sebuah Rumah Sakit dan tenaga medis untuk dapat meningkatkan kualitas pelayanannya. Pengguna pelayanan kesehatan mengharapkan sesuatu yang lebih untuk dapat meningkatkan kondisi kesejahteraanya. Ditambah lagi sibuknya para keluarga maupun wali dari seorang klien, sehingga perawat dan Rumah Sakit wajib memantau kondisi pasien sehingga mengurangi kondisi yang tidak diinginkan dan berdampak seperti cedera maupun terjadi kejadian yang fatal. Kejadian itu tentu menurunkan citra instanasi Rumah Sakit dan perawat.

\section{Tujuan}


Tujuan yang didapat dari penelitian ini yaitu untuk mengetahui kebijakan yang dilakukan untuk mendukung keselamatan pasien.

\section{Metode}

Metode yang digunakan dalam jenis penelitian ini adalah dengan metode deskriptif dimana penelitian dilakukan dengan pengumpulan data dari berbagai sumber seperti textbook dan jurnal.

\section{Hasil}

Dari hasil penelitian menunjukkan bahwa terdapat kebijakan yang mendukung tindakan keselamatan pasien. Kebijakan ini membawa arah positif, karena dengan adanya kebijakan yang telah diterapkan dapat meminimalisir angka kejadian yang tidak terduga dalam menangani kondisi keselamatan pasien. Dan kebijakan tersebut dapat mendukung kondisi pasien menjadi lebih baik. Sehingga Rumah Sakit dan tenaga medis memiliki tanggung jawab yang besar. Walaupun pada kenyataan nya tentu banyak kendala-kendala dalam menanganinya tapi itu menjadi sebuah motivasi sebuah instansi memperbaiki setiap kesalahan.

\section{Pembahasan}

Dalam UU No. 44 Tahun 2009 tentang Rumah Sakit, Pasal 43 ayat (1) mewajibkan Rumah Sakit menerapkan standar keselamatan pasien.

Dalam pasal 43 ayat (2),standar keselamatan pasien dilaksanakan melalui pelaporan insiden, menganalisa, dan mendapatkan pemecahan masalah dalam rangka menurunkan angka kejadian yang tidak diharapkan.

UU Tentang Kesehatan \& Rumah Sakit :

1. Keselamatan Pasien sebagai Isu Hukum 
a. $\quad$ Pasal 53 (3) UU No.36/2009

"Pelaksanaan Pelayanan kesehatanharus mendahulukan keselamatan nyawa pasien."

b. Pasal 32n UU No.44/2009

"Pasien berhak memperoleh keamanan dan keselamatan dirinya selama dalam perawatan di Rumah Sakit.

c. Pasal 58 UU No.36/2009

1) "Setiap orang berhak menuntut G.R terhadap seseorang, tenaga kesehatan, dan/atau penyelenggara kesehatan yang menimbulkan kerugian akibat kesalahan atau kelalaian dalam Pelkes yang diterimanya."

2) “....tidak berlaku bagi tenaga kesehatan yang melakukan tindakan penyelamatan nyawa atau pencegahan kecacatan seseorang dalam keadaan darurat."

2. Tanggung jawab Hukum Rumah sakit

a. Pasal 29b UU No.44/2009

"Memberi pelayanan kesehatan yang aman, bermutu, antidiskriminasi, dan efektif dengan mengutamakan kepentingan pasien sesuai dengan standar pelayanan Rumah Sakit.”

b. Pasal 46 UU No.44/2009

"Rumah sakit bertanggung jawab secara hukum terhadap semua kerugian yang ditimbulkan atas kelalaian yang dilakukan tenaga kesehatan di RS.”

c. Pasal 45 (2) UU No.44/2009

"Rumah sakit tidak dapat dituntut dalam melaksanakan tugas dalam rangka menyelamatkan nyawa manusia." 
3. Bukan tanggung jawab Rumah Sakit

Pasal 45 (1) UU No.44/2009 Tentang Rumah sakit

"Rumah Sakit Tidak bertanggung jawab secara hukum apabila pasien dan/atau keluarganya menolak atau menghentikan pengobatan yang dapat berakibat kematian pasien setelah adanya penjelasan medis yang kompresehensif. “

\section{Hak Pasien}

a. $\quad$ Pasal 32d UU No.44/2009

"Setiap pasien mempunyai hak memperoleh layanan kesehatan yang bermutu sesuai dengan standar profesi dan standar prosedur operasional"

b. Pasal 32e UU No.44/2009

"Setiap pasien mempunyai hak memperoleh layanan yang efektif dan efisien sehingga pasien terhindar dari kerugian fisik dan materi”

c. Pasal 32j UU No.44/2009

"Setiap pasien mempunyai hak tujuan tindakan medis, alternatif tindakan, risiko dan komplikasi yang mungkin terjadi, dan prognosis terhadap tindakan yang dilakukan serta perkiraan biaya pengobatan"

\section{d. $\quad$ Pasal 32q UU No.44/2009}

"Setiap pasien mempunyai hak menggugat dan/atau menuntut Rumah Sakit apabila Rumah Sakit diduga memberikan pelayanan yang tidak sesuai dengan standar baik secara perdata ataupun pidana" 
5. Kebijakan yang mendukung keselamatan pasien

Pasal 43 UU No.44/2009

1) RS wajib menerapkan standar keselamatan pasien

2) Standar keselamatan pasien dilaksanakan melalui pelaporan insiden, menganalisa, dan menetapkan pemecahan masalah dalam rangka menurunkan angka kejadian yang tidak diharapkan.

3) RS melaporkan kegiatan keselamatan pasien kepada komite yang membidangi keselamatan pasien yang ditetapkan oleh menteri

4) Pelaporan insiden keselamatan pasien dibuat secara anonym dan ditujukan untuk mengoreksi system dalam rangka meningkatkan keselamatan pasien.

Pemerintah bertanggung jawab mengeluarkan kebijakan tentang keselamatan pasien yang merupakan suatu system dimana rumah sakit membuat asuhan pasien lebih aman. System tersebut meliputi:
a. Assessment risiko
b. Identifikasi dan pengelolaan yang terkait resiko pasien
c. Pelaporan dan analisis insiden
d. Kemampuan belajar dari insiden
e. Tindak lanjut dan implementasi solusi meminimalkan resiko

Pengaplikasian dari keselamatan pasien adalah sebagai berikut:

1. Terdapat 9 solusi keselamatan Pasien di RS (WHO Collaborating Centre for Patient Safety, 2 May 2007:

1) Perhatikan nama obat, ucapan mirip dan rupa (look-alike, medication names) 


\section{2) Identifikasi pasien}

3) Komunikasi yang benar saat serah terima pasien

4) Lakukan tindakan yang benar pada sisi tubuh yang benar

5) Kendalikan cairan elektrolit yang pekat

6) Pada pengalihan pelayanan, pastikan akurasi pemberian obat

7) Hindari darikesalahan kateter dan sambung slang

8) Gunakan alat injeksi yang sekali pakai

9) Jaga kebersihan tangan untuk pencegahan infeksi nosokomial.

2. Terdapat 7 Standar Keselamatan Pasien (mengacu pada "Hospital Patient Safety Standards" yang dikeluarkan oleh Joint Commision on Accreditation of Health Organizations, Illinois, USA, tahun 2002:

\section{Hak pasien}

Standar :Pasien \& keluarganya mempunyai hak untuk mendapatkan informasi tentang rencana \& hasil pelayanan termasuk kemungkinan terjadinya KTD (Kejadian Tidak Diharapkan).

\section{Kriteria :}

1) Ada dokter penanggung jawab pelayanan

2) Dokter wajib membuat rencana pelayanan

3) Dokterwajib memberikan penjelasan yang jelas dan benar kepada pasien dan keluarga mengenai rencana dan hasil pelayanan, pengobatan atau prosedur untuk pasien termasuk kemungkinan terjadinya KTD 


\section{Mendidik pasien dan keluarga}

Standar : RS harus mendidik pasien \& keluarganya mengenai kewajiban \& tanggung jawab pasien dalam asuhan pasien.

Kriteria : RS harus ada system dan mekanisme mendidik pasien \& keluarganya mengenai kewajiban \& tanggung jawab pasien dalam asuhan pasien agar:

1) Dapat memberikan info yg benar, jelas, lengkap, dan jujur

2) Dapat mengetahui kewajiban dan tanggung jawab

3) Dapat mengajukan pertanyaan untuk hal yang tidak dimengerti

4) Dapat memahami dan menerima konsekuensi dari pelayanan

5) Dapat mematuhi instruksi serta menghormati peraturan RS

6) Dapat memperlihatkan sikap menghormatiserta tenggang rasa

7) Dapat memenuhi kewajiban finansial yangtelah disepakati

3. Keselamatan pasien dan kesinambungan pelayanan

Standar : RS dapat menjamin kesinambungan pelayanan sertakoordinasi antar tenaga dan antar unit pelayanan.

Kriteria :

1) Dapatmengkoordinasi pelayanan secara menyeluruh

2) Dapat mengkoordinasi pelayanan disesuaikan kebutuhan pasien dan kelayakan sumber daya

3) Dapat mengkoordinasi pelayanan mencakup peningkatan komunikasi 
4) Dapat mengkomunikasikan dan mentransfer informasi antar profesi kesehatan

4. Dapat melakukan evaluasi dan program peningkatan keselamatan pasien dengan penggunaan metode peningkatan kinerja

Standar : RS harus mendesign proses baru atau memperbaiki proses yg ada, meningkatkankeselamatan pasien, dan memonitor \& mengevaluasi kinerja melalui pengumpulan data, menganalisis secara intensif KTD, \& melakukan perubahan untuk peningkatan kinerja serta KP.

Kriteria :

1) Setiap rumah sakit melakukan proses perancangan (design)sesuai dengan "Tujuh Langkah Menuju Keselamatan Pasien Rumah Sakit”.

2) Setiap rumah sakit melakukan pengumpulan data kinerja

3) Setiap rumah sakit melakukan evaluasi intensif

4) Setiap rumah sakitmenggunakan semua data dan informasi hasil analisis

5. Peran kepemimpinan dalam meningkatkan keselamatan pasien

Standar :

1) Pimpinan dapat mendorong \&menjamin implementasi program $\mathrm{KP}$ melalui penerapan “7 Langkah Menuju KP RS”.

2) Pimpinan dapat menjamin berlangsungnya program mengurangi KTD \&proaktif identifikasi risiko KP.

3) Pimpinan dapat mendorong \&menumbuhkan komunikasi \& koordinasi antar unit \& individu yang berkaitan dengan pengambilan keputusan mengenai KP. 
4) Pimpinan dapat mengalokasikan sumber daya yg adekuat utk mengkaji, mengukur,dan meningkatkan kinerja RS serta tingkatkan KP.

5) Pimpinan dapat mengukur \& mengkaji efektifitas daru kontribusinyadalam meningkatkan kinerja RS \& KP.

\section{Kriteria :}

1) Terdapat tim antar disiplin yang dapat mengelola program keselamatan pasien.

2) Terdapat program proaktif untuk menidentifikasi risiko keselamatan dan program meminimalkan insiden

3) Terdapat mekanisme kerja untuk menjamin semua komponen dari rumah sakitdapat terintegrasi dan berpartisipasi

4) Terdapat prosedur "cepat-tanggap" terhadap insiden, termasuk asuhan kepada pasien yang terkena musibah, membatasi risiko pada orang lain dan penyampaian informasi untuk keperluan analisis yang benar dan jelas.

5) Terdapat mekanisme pelaporan eksternal dan internal berkaitan dengan insiden.

6) Terdapat mekanisme untuk menangani berbagai insiden

7) Terdapat komunikasi terbuka dan kolaborasi secara sukarela antar unit dan antar pengelola pelayanan.

8) Terdapat sumber daya dan sistem informasi yang dibutuhkan

9) Terdapat sasaran terukur, dan pengumpulan informasi menggunakan kriteria objektif sebagaievaluasi efektivitas perbaikan kinerja rumah sakit dan keselamatan pasien

6. Mendidik staf tentang keselamatan pasien 
Standar :

1) $\mathrm{RS}$ memiliki proses pendidikan, pelatihan \& orientasi mencakup keterkaitan jabatan dengan KP secara jelas.

2) RS menyelenggarakan pendidikan \& pelatihan yang berkelanjutan untuk meningkatkan \& memelihara kompetensi staf.

\section{Kriteria :}

1) memiliki program diklat dan orientasi bagi staf baru.

2) mengintegrasikan topik keselamatan pasien dalam setiap kegiatan inservice training.

3) menyelenggarakan pelatihan tentang kerjasama kelompok (teamwork).

7. Komunikasi merupakan kunci bagi staf untuk mencapai keselamatan pasien.

Standar :

1) RS merencanakan \& mendesain proses manajemen informasi KP.

2) Transmisi data \& informasi harus akuratdan tepat waktu.

Kriteria :

1) disediakan anggaran untuk merencanakan dan mendesain proses manajemen.

2) Tersedia mekanisme identifikasi masalah dan kendala komunikasi

Terdapat pula Langkah-langkah dari pengaplikasian keselamatan pasien:

a.Rumah Sakit

1. Rumah sakit dapat membentuk Tim Keselamatan Pasien Rumah Sakit, dengan 
susunan organisasi: Ketua: dokter, Anggota: dokter, dokter gigi, perawat, tenaga kefarmasian dan tenaga kesehatan lainnya.

2. Rumah sakit dapat mengembangkanpelaporaninternaltentang insiden dan sistem informasi pencatatan

3. Rumah sakit dapat melakukan pelaporan insiden ke Komite Keselamatan Pasien Rumah Sakit (KKPRS) dengan cara rahasia

4. Rumah Sakit dapat memenuhi standar keselamatan pasien rumah sakit dan juga dapat menerapkan tujuh langkah keselamatan pasien.

5. Rumah sakit pendidikan dapat mengembangkan standar pelayanan medis berdasarkan hasil analisis akar masalah dan untuk tempat pelatihan standar-standar yang baru saja dikembangkan.

b. Provinsi/Kabupaten/Kota

1. Melakukan advokasi program keselamatan pasien ke rumah wilayah tersebut.

2. Melakukan advokasi ke pemerintah daerah.

3. Melakukan pembinaan pelaksanaan program keselamatan pasien di rumah sakit wilayah

c. Pusat

1. Membentuk komite dibawah Perhimpunan Rumah Sakit Seluruh Indonesia

2. Menyusun panduan nasional mengenai Keselamatan Pasien Rumah Sakit

3. Melakukan sosialisasi dan advokasi program keselamatan pasien ke PERSI Daerah,Rumah sakit pendidikan, dan Dinas Kesehatan Propinsi/Kabupaten/Kota. 
4. Melakukanpengembangan laboratorium uji coba program keselamatanpasien.

Menurut Hasting G, 2006, terdapat8 langkahuntuk mengembangkan keselamatan pasien, yaitu:

1. Put the focus back on safety

2. Think small and make the right thing easy to do

3. Encourage open reporting

4. Make data capture a priority

5. Use systems-wide approaches

6. Build implementation knowledge

7. Involve patients in safety efforts

8. Develop top-class patient safety leaders

\section{Penutup}

Keselamatan pasien (Patient safety) adalah proses dalam suatu Rumah Sakit untuk memberikan pelayanan kepada pasien agar lebih aman. Dalam pelaksanaan keselamatan pasien ini terdapat banyak kebijakan baik yang terdapat dalam Undang-undang maupun badang organisasi kesehatan dunia. Kebijakan-kebijakan tersebut harus dilaksanakan dengan benar dan tepat agar proses pelaksanaan asuhan keperawatan dalam bidang keselamatan pasien ini dapat terlaksana dengan baik. Sebagai seorang tenaga medis, harus mempunyai pengetahuan mengenai keselamatan pasien agar tidak terjadi kesalahan dan berjalan sesuai ketentuan pengaplikasian yang berlaku.

\section{Referensi}


Anggraeni, Hakim \& Widjiati. (2014). Evaluationon Patient Identification System Implementation in Hospital's Inpatient Unit. Jurnal Kedokteran Brawijaya, Vol. 28, Suplemen No. 1.

Arruum, D., Salbiah, \& Manik, M. (2015). Pengembangan Sistem Manajemen Risiko Keselamatan Pasien di Rumah Sakit Universitas Sumatera Utara: (Model Pengembangan Manajemen Mutu). Medan: Lowa State U niversity Press.

Aryani. (2009). Analisis pengetahuan dan motivasi perawat yang mempengaruhi sikap mendukung pemaparan program patient safety diinstalasi perawa an intensif di RSUD Dr. Moewardi Surakarta. TESIS, Tidak Dipublikasikan. Semarang: Program Pasca Sarjana UNDIP.

Budiono, S. (2014). Pelaksanaan Program Manajemen Pasien dengan Risiko Jatuh di Rumah Sakit. Jurnal Kedokteran Brawijaya. 28 (1), 78-83.

Cahyono, J. (2008). Membangun Budaya Keselamatan Pasien dalam Praktik Kedokteran. Yogyakarta: Penerbit Kanisius.

Departemen Kesehatan RI. (2006). Panduan Nasional Keselamatan Pasien Rumah Sakit (Patient Safety). Jakarta: Dep Kes RI.

Departemen Kesehatan RI. (2007). Panduan Nasional Keselamatan Pasien Rumah Sakit (Patient Safety). Edisi 2. KKP-RS.

Harus, B. D. A. S. (2015). Pengetahuan Perawat Tentang Keselamatan Pasiendengan Palaksanaan Prosedur Keselamatan Pasien Rumah Sakit Panti Waluyo Sawahan Malang. CARE, 3(1),25-32.

Kemenkes, R. (2013). Panduan Keselamatan Pasien. Jakarta: DepKes RI.

KKP-RS. 2008. Pedoman Pelaporan Keselamatan Pasien. Jakarta: KKP-RS.

Kusumapraja, R. (2011). Perencanaan Kebutuhan Tenaga Perawat di RS. Makalah Manajemen Keperawatan. RSU Persahabatan. Jakarta.

Mudayana, A. A. (2015). Pelaksanaan Patient Safety oleh Perawat di RSPKU Muhammadiyah Yogyakarta. Jurnal Kesehatan samodra Ilmu, 06 (02), 145-149. 
Perry \& Potter. (2005). Fundamental Keperawatan: Konsep Proses dan Praktek. Jakarta. Salemba Medika.

Phillips. J. J. (2011). Accountability in Human Resource Management. Routledge.

Riwayati. (2007). Hubungan Tingkat Pendidikan Dan Lama Kerja Perawat dengan Penerapan Prinsip "Enam Tepat” dalam Pemberian Obat di Ruang Rawat Inap $R S$ dr. Kariad I Semarang. Jurnal unimus. 1(1), 1-10.

Rumampuk, M. V.H. (2013). Peran Kepala Ruangan Melakukan Super visi Perawat dengan Penerapan Patient Safety di Ruang Rawat Inap Rumah Sakit. Jurnal Unhas. 5(4). 254-62.

Simamora, R. H. (2018). Buku Ajar Keselamatan Pasien Melalui Timbang Terima Pasien Berbasis Komunikasi Efektif: SBAR.

Suryanto, D. T. H. (2018). Hubungan Budaya Keselamatan Pasien dengan Pelaporan Insiden Keselamatan Pasienoleh Perawat di Ruang Rawat Inap Rumah Sakit. Medan: Program Studi Magister Ilmu Keperawatan USU. 